\title{
Facial paralysis for the plastic surgeon
}

\author{
Aaron M Kosins BS, Keith A Hurvitz MD, Gregory RD Evans MD FACS, Garrett A Wirth MD
}

\begin{abstract}
AM Kosins, KA Hurvitz, GRD Evans, GA Wirth. Facial paralysis for the plastic surgeon. Can J Plast Surg 2007;15(2):77-82.
\end{abstract}

Facial paralysis presents a significant and challenging reconstructive problem for plastic surgeons. An aesthetically pleasing and acceptable outcome requires not only good surgical skills and techniques, but also knowledge of facial nerve anatomy and an understanding of the causes of facial paralysis.

The loss of the ability to move the face has both social and functional consequences for the patient. At the Facial Palsy Clinic in Edinburgh, Scotland, 22,954 patients were surveyed, and over 50\% were found to have a considerable degree of psychological distress and social withdrawal as a consequence of their facial paralysis. Functionally, patients present with unilateral or bilateral loss of voluntary and nonvoluntary facial muscle movements. Signs and symptoms can include an asymmetric smile, synkinesis, epiphora or dry eye, abnormal blink, problems with speech articulation, drooling, hyperacusis, change in taste and facial pain.

With respect to facial paralysis, surgeons tend to focus on the surgical, or 'hands-on', aspect. However, it is believed that an understanding of the disease process is equally (if not more) important to a successful surgical outcome. The purpose of the present review is to describe the anatomy and diagnostic patterns of the facial nerve, and the epidemiology and common causes of facial paralysis, including clinical features and diagnosis. Treatment options for paralysis are vast, and may include nerve decompression, facial reanimation surgery and botulinum toxin injection, but these are beyond the scope of the present paper.

Key Words: Bell palsy; Facial nerve trauma; Facial palsy; Facial paralysis; Herpes zoster oticus

\section{ANATOMY OF THE FACIAL NERVE}

$\mathrm{C}$ llectively, the facial nerve (cranial nerve VII) mediates facial movements, and contributes to taste, auricular sensation and parasympathetic innervations to the lacrimal, submandibular and sublingual glands (Figure 1).

Corticobulbar contribution to the facial nerve is important to understand clinically how to differentiate a central or upper motor neuron insult from a peripheral nerve or lower motor neuron insult. An upper motor neuron lesion, such as a stroke of the motor cortex or internal capsule, results in weakness of the contralateral lower facial musculature with preservation of facial tone and spontaneous facial movements of the upper facial musculature. Voluntary control of the forehead musculature is retained, because the upper face receives contribution from both ipsilateral and contralateral motor cortices. In contrast, the lower face receives contribution from only the ipsilateral motor cortex. Consequently, lower motor neuron lesions result in ipsilateral paralysis of both the upper and lower face (Figure 2).

\section{La paralysie faciale et le chirurgien plasticien}

La paralysie faciale pose un problème de taille au chirurgien plasticien. L'obtention de résultats acceptables et satisfaisants sur le plan esthétique exige non seulement une grande compétence et de bonnes techniques chirurgicales mais aussi une bonne connaissance de l'anatomie des nerf faciaux et une bonne compréhension des causes de la paralysie faciale. L'incapacité de mouvoir le visage a des conséquences sociales et fonctionnelles. D'après une enquête menée à la Facial Palsy Clinic, à Édimbourg, en Écosse, auprès de 22954 patients, plus de 50 \% d'entre eux ont fait état d'une grande détresse psychologique et de retrait social en raison de leur paralysie faciale. Sur le plan fonctionnel, les patients présentent une perte, unilatérale ou bilatérale, de mouvement des muscles faciaux, volontaires et involontaires. Les signes et symptômes peuvent comprendre un sourire asymétrique, la syncinésie, l'épiphora ou une sécheresse des yeux, un clignement anormal, des troubles de l'élocution, l'écoulement de la bave, l'hyperacousie, l'altération du goût ou la douleur faciale.

En ce qui concerne la paralysie faciale, les chirurgiens ont tendance à mettre l'accent sur l'aspect technique ou chirurgical comme tel de l'intervention. Cependant, on croit qu'une bonne compréhension du processus pathologique est aussi importante, sinon plus, pour l'obtention de résultats satisfaisants. Le présent examen a pour but de passer en revue l'anatomie des nerfs faciaux et les schémas de diagnostic, l'épidémiologie et les principales causes de la paralysie faciale, ainsi que les aspects cliniques et les diagnostics. Il existe un large éventail de traitements possibles de la paralysie faciale, dont la décompression nerveuse, la chirurgie de revitalisation faciale et les injections de toxine botulinique, mais cela dépasse le cadre du présent article.

Aesthetic $\mathcal{E}$ Plastic Surgery Institute, University of California, Irvine, California, USA

Correspondence: Dr Garrett A Wirth, Aesthetic Eु Plastic Surgery Institute, University of California, Irvine, Suite \#650 - 200 South Manchester,

Orange, California 92868-3298, USA. Telephone 714-456-5253, fax 714-456-7718, e-mail gwirth@uci.edu 


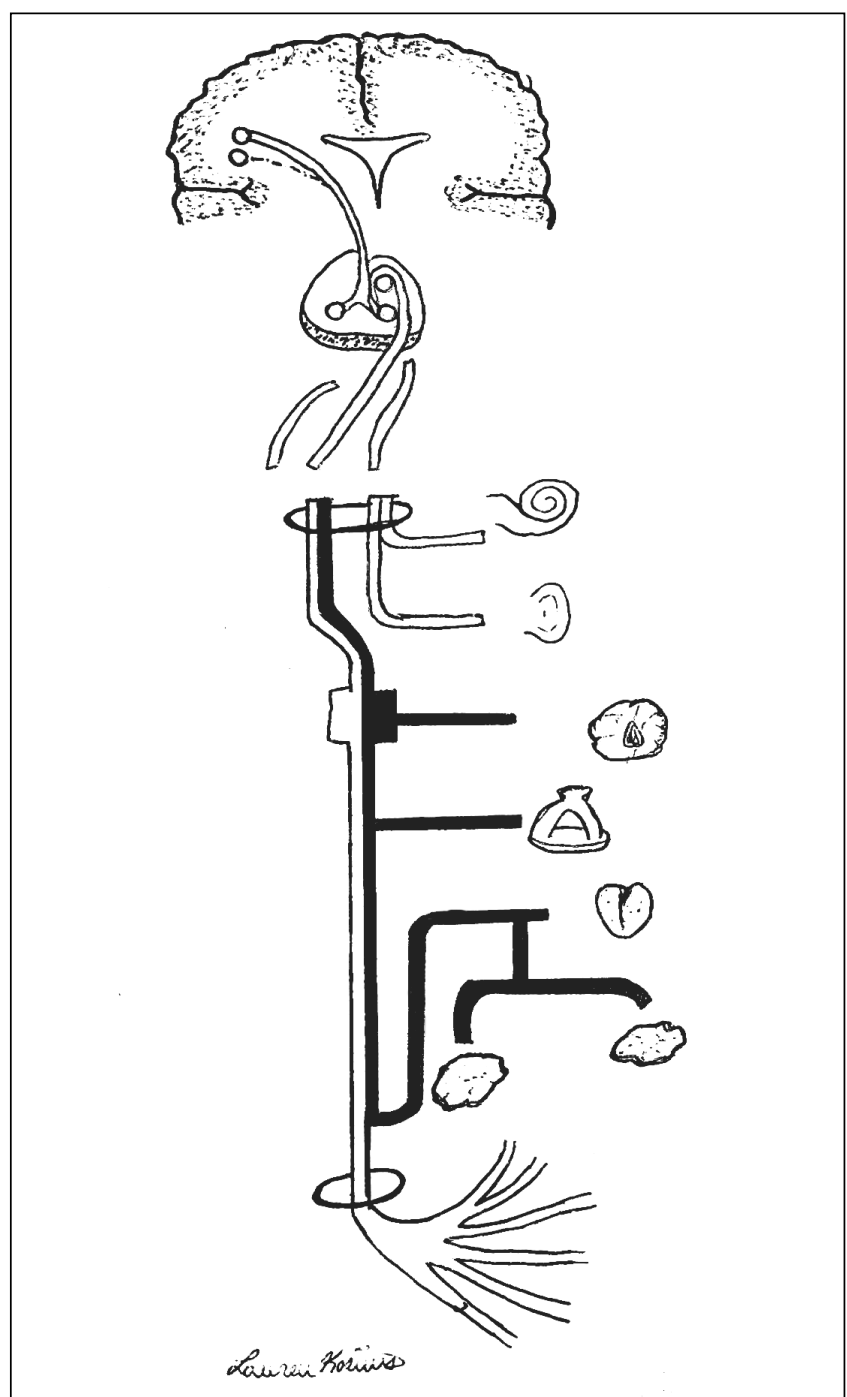

Figure 1) A diagram of the origins and contributions of the facial nerve throughout its course. The facial nerve contributes to hearing and balance, the lacrimal gland, the stapes, the tongue, the submandibular and sublingual glands, and the facial musculature, respectively

parasympathetic functions (eg, lacrimal or salivary flow) may be unaffected by slow-growing lesions at or proximal to the ganglion. Clinically, it is important to note that the labyrinthine segment is the narrowest region within the temporal bone (approximately $0.7 \mathrm{~mm}$ in diameter). Therefore, any swelling of the nerve most likely results in compression in this area (1).

Distal to the geniculate ganglion, the facial nerve courses through the tympanic portion of the facial canal just behind the cochleariform process and tensor tympani tendon in the middle ear. The facial nerve then continues above the oval window and stapes as it approaches the mastoid segment. Within the tympanic portion, no branching occurs.

The mastoid segment begins at the second sharp bend (genu) in the facial canal, where the nerve courses inferiorly toward the stylomastoid foramen. This segment of the facial nerve gives off the next three branches of the facial nerve: the nerve to the stapedius muscle, a sensory auricular branch that provides sensation to the posterior external auditory canal, and the chorda tympani nerve, which passes across the middle ear

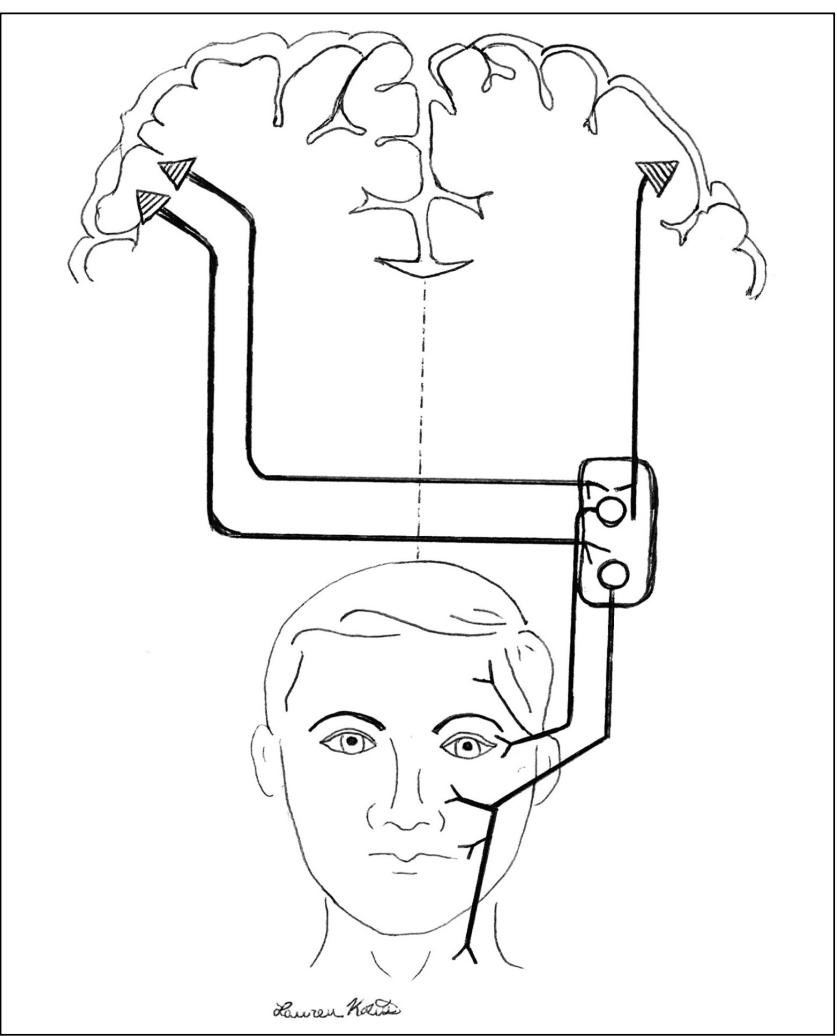

Figure 2) A diagram of the contributions of the facial nerve to the upper and lower face. The upper face receives bilateral contributions, while the lower face receives only contralateral contribution

before joining the lingual nerve. The chorda tympani nerve supplies parasympathetic innervation to the submandibular and sublingual glands, as well as taste sensation to the anterior two-thirds of the tongue via special visceral afferents.

Finally, cranial nerve VII exits the skull base through the stylomastoid foramen (as a purely motor nerve), courses through the parotid gland and innervates the muscles of facial expression. As the nerve exits the stylomastoid foramen, it passes anteriorly to the posterior belly of the digastric muscle, and laterally to the external carotid artery and styloid process of the temporal bone. Branches are given off to the posterior digastric, stylohyoid and postauricular muscles before the nerve splits into its upper and lower main divisions at the posterior edge of the parotid gland.

The zygomaticofrontal and cervicofacial divisions of the facial nerve divide the parotid gland into superficial and deep lobes. Within the gland, the nerve further divides, and several branching patterns of the facial nerve can be seen (2). Most commonly, the upper division gives off the frontal (temporal), zygomatic and buccal branches. The lower division gives off the mandibular and cervical branches of the facial nerve. Together, these five branches form a rich plexus of nerve fibres that innervate the 13 paired facial muscles. Upon leaving the parotid, the five main branches of the facial nerve can have up to 15 subsequent branches with further arborization and interconnection distally. The net effect is a functional overlap between the many branches as they course to their respective muscles. For example, a zygomaticobuccal branch may supply innervation to both the orbicularis oculi and the orbicularis oris. 


\section{TABLE 1}

\section{Causes of facial paralysis}

Idiopathic causes
Bell's palsy, sarcoidosis, inherited Bell's palsy, myasthenia gravis,
multiple sclerosis, temporal arteritis
Infection
External otitis, varicella zoster, syphilis, otitis media, poliomyelitis,
botulism, mastoiditis, coxsackievirus, tetanus, diptheria, HIV,
cholesteatoma, Lyme disease
Neoplastic causes
Schwannoma, teratoma, meningioma, von Recklinghausen's disease,
hemangioma, parotid tumour, sarcoma, carcinoma (metastatic)
Congenital causes
Möbius syndrome
Neurological causes
Opercular syndrome, Wernicke-Korsakoff syndrome, pseudotumor cerebri,
lacunar infarct
Trauma
Traumatic delivery, parotid surgery, forceps delivery, anaesthetic nerve
block, mandible fracture, penetrating injury, scuba diving
Toxins
Ethylene glycol, ethanol, thalidomide

\section{EPIDEMIOLOGY OF FACIAL PARALYSIS}

Facial paralysis is not an uncommon problem, and the annual incidence has been estimated to be approximately 70 cases per 100,000 population $(3,4)$. Furthermore, in a study published by Bleicher et al (5), it was estimated that approximately 127,000 cases of permanent facial paralysis occur annually. Peripheral facial paralysis remains a diagnostic challenge. Every effort must be made to determine the cause so that appropriate treatment can be initiated (observation, pharmacology, and/or surgery). The Bell's Palsy Research Foundation (formerly the National Centers for Facial Paralysis) groups the causes into seven general categories: idiopathic, infectious, neoplastic, birth, neurological, traumatic and toxic (6). Table 1 lists the different causes of facial paralysis. The most common causes of adult facial paralysis are Bell's palsy, trauma, herpes zoster oticus and neoplasia (schwannoma is the most common of the neoplasms) (4). In the pediatric population, Bell's palsy is still the most common cause of facial paralysis, followed by trauma, birth (congenital or acquired), infection and neoplasia (osseous hemangioma is the most common of the neoplasms). Terrance Cawthorne once stated that "all that palsies is not Bell's." (7). There are many potential etiologies, and the list continues to grow as physicians continue to increase their diagnostic capabilities.

The present paper reviews the features, diagnosis and selected treatments of the most common causes of facial paralysis.

\section{Bell's palsy}

\section{ETIOLOGY OF FACIAL PARALYSIS}

The most common cause of facial paralysis is Bell's palsy, which results from an idiopathic insult to the facial nerve (Figure 3). Therefore, the terms 'Bell's palsy' and 'idiopathic facial paralysis' are often used synonymously. The first description of the facial nerve and facial nerve palsy was by Sir Charles Bell in the early 1800s (8). The annual incidence

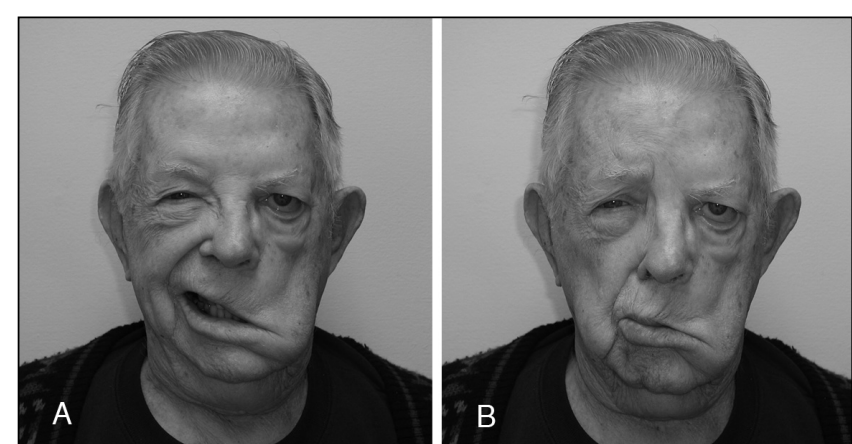

Figure 3) Unilateral facial paralysis caused by Bell's palsy

of Bell's palsy is estimated to be between 13 and 34 cases per 100,000 population $(9,10)$. Bell's palsy does not have a predilection for any race, sex or ethnicity. However, diabetes is present in $5 \%$ to $10 \%$ of afflicted patients, and facial paralysis is three times more common during pregnancy - especially in the later stages of pregnancy (11).

The exact cause of Bell's palsy has been debated for many years. It is believed that the disease is viral in origin, with resulting edema and secondary demyelination of the nerve. Herpes simplex virus is the suspected culprit based on serological evidence (12). Currently, polymerase chain reaction DNA testing supports the diagnosis of a reactivated virus, and herpes simplex virus-1 DNA has been found in approximately $79 \%$ of Bell's palsy patients (13). Although this proves the presence of the virus, it does not necessarily link causation of Bell's palsy. It should be noted that other viruses have been cultured from patients with Bell's palsy, including cytomegalovirus, EpsteinBarr virus, adenovirus, rubella, mumps and coxsackievirus. Whatever the cause, strict guidelines must be used to identify cases of Bell's palsy.

The history of onset and associated deficits are important characteristics used to verify the diagnosis of Bell's palsy. Bell's palsy is a diagnosis of exclusion using the following criteria:

- a variable prodrome with ear pain and hyperacusis occurring in $60 \%$ of patients;

- an acute onset (one to two days);

- diffuse seventh nerve involvement causing facial paresis/paralysis of all motor branches on the affected side, with variable involvement of taste, lacrimation and salivation;

- spontaneous recovery in approximately six months; and

- most importantly, no other attributable cause.

The diagnosis of Bell's palsy is often clinical. However, imaging may be warranted if signs are atypical, if the disease progresses beyond three weeks or if there is no sign of recovery within three months (4). Bone details are well visualized on computed tomography (CT) scans; however, magnetic resonance imaging with and without contrast is the gold standard to delineate soft tissue, including the nerve.

Histopathology of this disorder reveals an edematous nerve with compression by the epineurium (14). This strangulation of the nerve results in loss of nerve conduction, which is best demonstrated by electromyography. Motor nerve conduction values have been shown to correlate histologically with the number of degenerating motor neurons (15). 


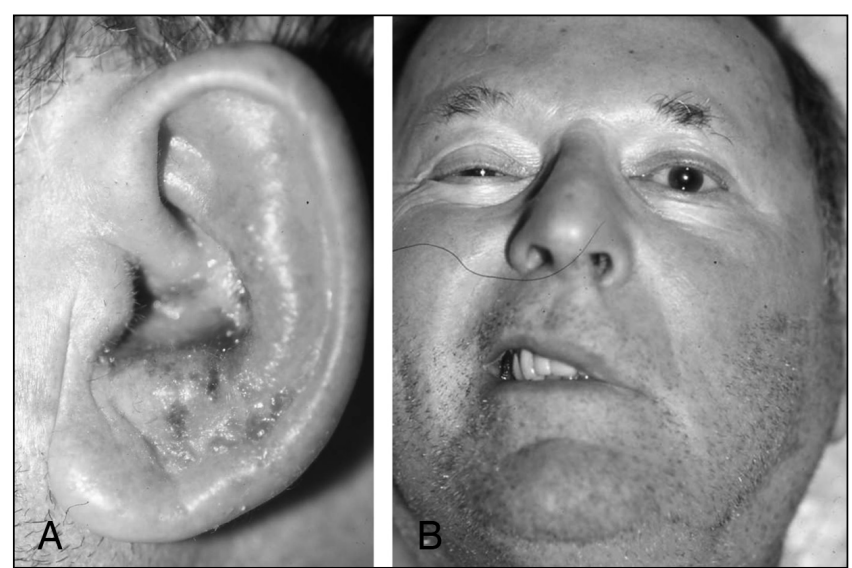

Figure 4) The auricular vesicles (A) and unilateral facial palsy (B) associated with Ramsey-Hunt syndrome

There are several prognostic indicators for Bell's palsy. The two most important are the completeness of the lesion and the time of onset of recovery. Clinically, incomplete lesions tend to recover well. In a landmark study of 1011 patients (9), 94\% of patients with incomplete palsies recovered normal function, compared with $60 \%$ with complete palsies. Furthermore, prognosis is favourable if a patient recovers partial function within the first three weeks of onset (16). If recovery does not begin until two to four months after onset, recovery is often incomplete and unsatisfactory.

Therapy for Bell's palsy remains controversial. Therapy is most effective when antivirals and steroids are started within $72 \mathrm{~h}$ of facial paralysis (17). Randomized clinical trials do not appear to support corticosteroids alone for treatment, even though one meta-analysis demonstrated a benefit (18). The efficacy of early treatment of Bell's palsy with acyclovir plus prednisolone remains promising. The recommended dose is $40 \mathrm{mg} /$ day to $60 \mathrm{mg} /$ day of prednisolone and $2000 \mathrm{mg} /$ day of acyclovir. Hato et al (19) demonstrated that when this combination was given within three days of onset, $100 \%$ of patients had complete recovery of function. Furthermore, the overall recovery rate was $95.7 \%$ in patients treated with combination therapy compared with $88.6 \%$ in patients treated with steroids alone (19). It should be noted that valacyclovir (1 $\mathrm{g}$ administered orally three times a day for seven days) is the preferred treatment along with steroids because there is greater drug absorption (compared with acyclovir, which needs to be taken five times per day) (20).

\section{Accidental and surgical trauma}

After Bell's palsy, the second most common cause of facial paralysis is trauma (accidental or surgical), which accounts for approximately $23 \%$ of facial paralysis cases $(4,21)$. Sharp injuries, penetrating wounds, avulsions and burns are some accidental causes of facial nerve injury. Temporal bone fracture secondary to a motor vehicle accident is currently the most common cause of traumatic paralysis (4).

The most common cause of facial paralysis due to surgical trauma is secondary to removal of an acoustic tumour or other lesion at the cerebellopontine angle (22). In fact, iatrogenic injury to the facial nerve is one of the most feared complications when performing surgery of the temporal bone. Another form of surgical trauma often associated with facial nerve injury involves parotid gland manipulation. It is important to note that following manipulation (such as routine superficial parotidectomy), many patients may transiently lose function but often have a full recovery (transient neuropraxia).

\section{Ramsey-Hunt syndrome (herpes zoster oticus)}

Ramsey-Hunt syndrome, also known as herpes zoster oticus, is caused by the varicella zoster virus. Of 3650 patients diagnosed with facial paralysis between 1963 and 1996, 7\% of patients were diagnosed with Ramsey-Hunt syndrome (4). Following infection by the virus, a geniculate ganglionitis causes a prodrome of ear pain and vesicle formation on the auricle, with or without vesicles on the face, neck or mouth (Figure 4). Following the prodrome, patients develop acute facial paralysis and commonly a loss of taste. In up to $40 \%$ of patients, there is also involvement of cranial nerve VIII, which results in sensineuronal hearing loss and vertigo (4).

Clinically, the presence of vesicles are necessary to validate the diagnosis and to distinguish Ramsey-Hunt syndrome from Bell's palsy. Unfortunately, only $60 \%$ of Ramsey-Hunt patients recover facial function (4). However, Ramsey-Hunt syndrome rarely recurs, whereas Bell's palsy has a $12 \%$ recurrence rate. Patients may be treated with steroids and acyclovir or valacyclovir in a similar fashion to Bell's palsy patients.

\section{Neoplasm}

Tumours of the head, neck and skull base may lie adjacent to and/or invade the facial nerve. Up to $5 \%$ of facial paralysis cases are due to a neoplastic process (4). Therefore, viewing of the parotid gland, skull base and stylomastoid foramen with magnetic resonance imaging or CT scan is imperative if suggestive signs or symptoms are present. A key diagnostic determination is the time of onset of facial paralysis. A prolonged, relapsing, or slowly progressive onset is suggestive of a neoplasm (23). Other potential signs of a neoplastic etiology include involvement of select branches of the facial nerve or absence of recovery. Of note, there can be instances in which a sudden and complete paralysis occurs, mimicking the presentation of Bell's palsy (24-26). A thorough history and physical examination is imperative in all cases to establish the underlying etiology.

The most common tumour to affect cranial nerve VII is a schwannoma. However, other tumours to consider are parotid tumours, neurofibromas, germ cell tumours and sarcomas. Meningiomas and hemangiomas have also been known to cause compression of the facial nerve.

\section{Congenital facial paralysis}

Congenital facial paralysis, by definition, is present at birth and occurs in almost two of 1000 newborns (27). Hemifacial microsomia is the most common unilateral syndromic condition associated with facial paralysis, while Möbius syndrome is the most common bilateral syndromic condition. With either syndrome, various tissues of the face can be affected, including the seventh nerve and its associated musculature. The effects of congenital facial paralysis tend to gradually worsen as the influence of gravity and aging prevail. Therefore, it is imperative to identify the deficit as soon as possible.

Fortunately, congenital cranial nerve palsies are relatively rare. Möbius syndrome, however, deserves special mention, because its effects are so disabling. The syndrome occurs in one of 200,000 live births. There are two competing theories of etiology. The first describes an inherent mesodermal defect, with aplasia of muscles and secondary nerve atrophy. The 
second implicates an ectodermal defect of the brain and secondary muscular dysfunction.

Möbius syndrome is a congenital, bilateral diplegia (with unilateral variations) with associated abducens nerve palsies (Figure 5). The syndrome may have genetic transmission, because it can run in families, and linkage analysis suggests inheritance on the long arm of chromosome 3 (28). There are often multiple cranial nerve deficits (III, IV, VI, IX, X and XII), as well as deformities of the tongue, jaw, and limbs (such as club foot, ectrodactyly and polydactyly). It can also be associated with the Pierre Robin sequence (micrognathia, cleft palate and glossptosis) and Poland's anomaly (abnormal development of pectoralis muscles and brachysymphalangism). Clinically, patients have an immobile mask-like face, but sometimes the upper lip is spared. The underlying cause of this lesion is unknown, although infection, alcohol, tobacco, drugs and a poorly oxygenated placenta have all been implicated (29).

\section{Less common causes}

Other infections (otitis media with or without cholesteatoma, Lyme disease, HIV) and inflammatory disorders (temporal arteritis, sarcoidosis) account for $3.5 \%$ of facial paralysis patients (4). Furthermore, bacterial infections of the middle ear account for over one-half of the infectious disease cases. Physical examination of the tympanic membrane and middle ear in addition to a CT scan of the temporal bone can help to rule out a middle ear etiology. Lyme disease, caused by Borrelia burgdorferi infection, can cause cranial neuropathy with associated facial paralysis that often resolves within two months. Treatment consists of antibiotic therapy with doxycycline or erythromycin. HIV infection can also directly cause facial palsy, usually at the time of seroconversion when a cerebrospinal fluid lymphocytosis is present (30). However, in the later stages of AIDS, paralysis is more often due to opportunistic infections. Sarcoidosis should also be considered in patients with bilateral facial palsy. For other less common causes of facial paralysis, please refer to Table 1.

\section{CONCLUSIONS}

Although facial paralysis is a clinical sign and not a disease, it mandates a thorough diagnostic evaluation and coordinated treatment plan. The loss of the ability to move the face has both social and functional consequences for the patient (31). Functionally, patients present with unilateral or bilateral loss of voluntary and nonvoluntary facial muscle movements. Signs and symptoms can include an asymmetric smile, synkinesis, epiphora or dry eye, abnormal blink, problems with speech articulation, drooling, hyperacusis, change in taste and facial pain. Arrangements must be made for physical therapy, speech therapy or occupational therapy as needed. At times, resolution of paralysis is incomplete or nonexistent. Operative treatment of facial paralysis remains a challenging problem. Nerve repair, nerve substitution techniques, muscle transposition, free muscle transfers and reanimation techniques are a partial list of therapies used to restore function to the facial nerve. In the past three decades, a vast amount of new information has been generated regarding the facial nerve and the restoration of function. Plastic surgeons continue to develop new, innovative techniques, which stand to improve the results of facial nerve repair, facial nerve function and outcomes of facial animation surgery. By understanding

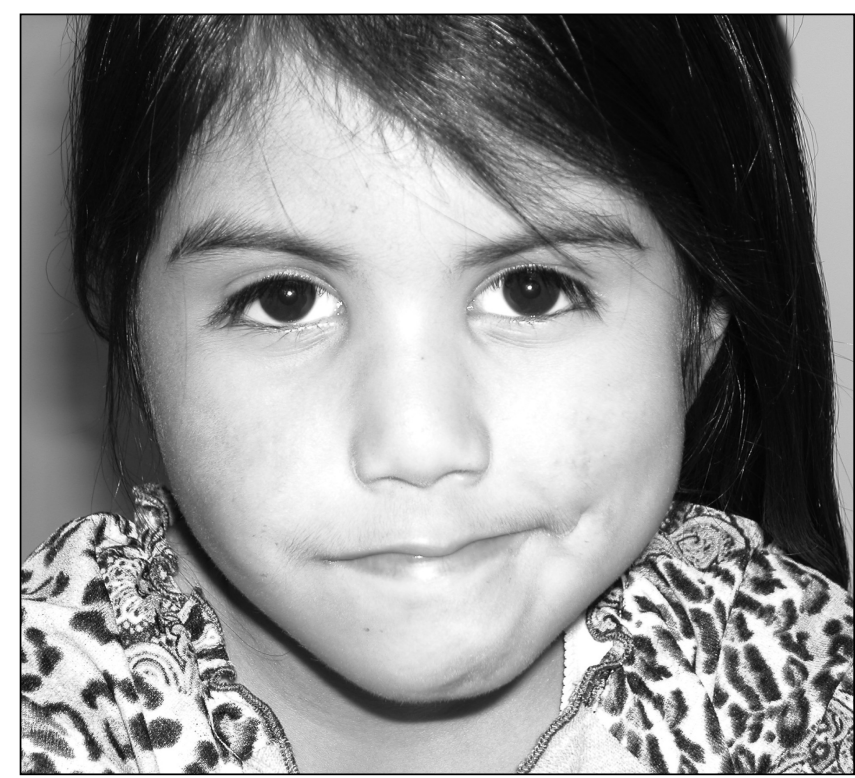

Figure 5) Status of a patient with unilateral Möbius syndrome following gracilis free flap reconstruction

the underlying background behind facial paralysis, plastic surgeons will continue to improve the outcome of such a devastating affliction.

ACKNOWLEDGEMENTS: The authors thank Lauren Kosins for her artwork submissions of Figures 1 and 2, and Dr Timothy F Kelley MD for his submission of Figures 4A and 4B.

\section{REFERENCES}

1. Fisch U, Esslen E. Total intratemporal exposure of the facial nerve. Pathologic findings in Bell's palsy. Arch Otolaryngol 1972;95:335-41.

2. Baker DC, Conley J. Avoiding facial nerve injuries in rhytidectomy. Anatomical variations and pitfalls. Plast Reconstr Surg 1979;64:781-95.

3. May M, Hardin WB Jr. Facial palsy: Interpretation of neurologic findings. Trans Sect Otolaryngol Am Acad Ophthalmol Otolaryngol 1977;84:710-22.

4. May M, Schaitkin B, Shapiro A. The Facial Nerve. New York: Thieme, 2001.

5. Bleicher JN, Hamiel S, Gengler JS, Antimarino J. A survey of facial paralysis: Etiology and incidence. Ear Nose Throat J 1996;75:355-8

6. The Bell's Palsy Research Foundation. What is Facial Paralysis and What are the Causes?

<www.bellspalsy.com/facialparalysis.htm\#WhatisFacialParalysis> (Version current at April 23, 2007).

7. Cawthorne T. The pathology and surgical treatment of Bell's palsy. J Laryngol Otol 1951;65:792-804.

8. Bell C. On the nerves, giving an account of some experiments on their structure and functions, which leads to a new arrangement of the system. Trans R Soc Lond (Phil) 1821;3:398.

9. Bell C. The Nervous System of the Human Body. London: Longman, 1830.

10. Peitersen E. The natural history of Bell's palsy. Am J Otol 1982;4:107-11.

11. Hilsinger RL Jr, Adour KK, Doty HE. Idiopathic facial paralysis, pregnancy, and the menstrual cycle. Ann Otol Rhinol Laryngol $1975 ; 84: 433-42$.

12. Hunt JR. On herpetic inflammation of the geniculate ganglion: A new syndrome and its complications. J Nerv Ment Dis 1907;34:73-96.

13. Murakami S, Mizobuchi M, Nakashiro Y, Doi T, Hato N, Yanagihara N. Bell's palsy and herpes simplex virus: Identification 
of viral DNA in endoneurial fluid and muscle. Ann Intern Med 1996;124:27-30.

14. Liston SL, Kleid MS. Histopathology of Bell's palsy. Laryngoscope 1989;99:23-6.

15. Halvorson D, Coker N, Wang-Bennett L. Histologic correlation of the degenerating facial nerve with electroneurography. Laryngoscope 1993;103:178-84.

16. Jabor MA, Gianoli G. Management of Bell's palsy. J La State Med Soc 1996;148:279-83.

17. Adour KK, Ruboyianes JM, Von Doersten PG, et al. Bell's palsy treatment with acyclovir and prednisone compared with prednisone alone: A double-blind, randomized, controlled trial. Ann Otol Rhinol Laryngol 1996;105:371-8.

18. Ramsey M, DerSimonian R, Holltel M, Burgess L. Corticosteroid treatment for idiopathic facial nerve paralysis: A meta-analysis. Laryngoscope 2000;110:335-41.

19. Hato N, Matsumoto S, Kisaki H, et al. Efficacy of early treatment of Bell's palsy with oral acyclovir and prednisolone. Otol Neurotol 2003;24:948-51.

20. Knox GW. Treatment controversies in Bell palsy. Arch Otolaryngol Head Neck Surg 1998;124:821-3.

21. McCabe BF. Injuries to the facial nerve. Laryngoscope 1973;82:1891-6.
22. May M. Management of cranial nerves I through VII following skull base surgery. Otolaryngol Head Neck Surg 1980;88:560-75.

23. Smith CK, Portelli FR, Hermann LK, Walike JW. Facial palsy caused by facial nerve tumor. Laryngoscope 1971;81:1542-5.

24. Schlieter M, Zoubaa S, Kress B, Unterberg A, Jacobi C, Hahnel S. Hemorrhagic acoustic schwannoma: Radiological and histopathological findings. J Neuroradiol 2005;32:210-2.

25. Ho TP, Carrie S, Meikle D, Wood KM. T-cell lymphoma presenting as acute mastoiditis with a facial palsy. Int J Pediatr Otorhinolaryngol 2004;68:1199-201.

26. Marzo SJ, Leonetti JP, Petruzzeli G. Facial paralysis caused by malignant skull base neoplasms. Neurosurg Focus 2002;12:e2.

27. Falco NA, Eriksson E. Facial nerve palsy in the newborn: Incidence and outcome. Plast Reconstr Surg 1990;85:1-4.

28. Kremer H, Kuyt LP, van den Helm B, et al. Localization of a gene for Mobius syndrome to a chromosome $3 \mathrm{q}$ by linkage analysis in a Dutch family. Hum Mol Genet 1996;5:1367-71.

29. Rubin L. Congenital facial paralysis, including Mobius syndrome. In: Rubin L, ed. The Paralyzed Face. St Louis: Mosby, 1991:80-5.

30. Murr AH, Benecke JE Jr. Association of facial paralysis with HIV positivity. Am J Otol 1991;12:450-51.

31. Weir A, Pentland B, Murray J, et al. Bell's palsy: The effect of self image, mood state and social activity. Clin Rehabil 1993;7:88-90. 